Research Paper

\title{
Antifungal susceptibility of clinical and environmental Cryptococcus neoformans and Cryptococcus gattii isolates in Jabalpur, a city of Madhya Pradesh in Central India
}

\author{
Ruchi Sethi Gutch ${ }^{1,2}$, Shesh Rao Nawange ${ }^{1,2}$, Shankar Mohan Singh ${ }^{1,2}$, \\ Ruchika Yadu $^{1,2}$, Aditi Tiwari ${ }^{1,2}$, Richa Gumasta ${ }^{1,2}$, Arvind Kavishwar ${ }^{3}$ \\ ${ }^{1}$ Department of Biological Sciences, Rani Durgavati University, Madhya Pradesh, India. \\ ${ }^{2}$ Centre for Medical Mycology, Fungal Disease Diagnostic and Research Center, Madhya Pradesh, India. \\ ${ }^{3}$ National Institute For Research In Tribal Health, Madhya Pradesh, India.
}

Submitted: July 8, 2014; Approved: December 28, 2014.

\begin{abstract}
In this study, we present antifungal susceptibility data of clinical and environmental isolates of Central Indian Cryptococcus neoformans (Serotype A, $\mathrm{n}=8$ and $\mathrm{n}=50$ respectively) and Cryptococcus gattii (Serotype B, $n=01$ and $n=04$ respectively). Susceptibilities to fluconazole, itraconazole and ketoconazole were determined by using NCCLS broth micro-dilution methodology. The total number of resistant strains for fluconazole in case of $C$. neoformans and $C$. gattii showed a significant difference by using chi-square test $\left(\mathrm{p}<0.05^{*}\right)$, while considering fisher's exact $\mathrm{p}$ value was nonsignificant $(\mathrm{p}>0.05)$. However, the total number of resistant strains for itraconazole and ketoconazole was not found statistically significant. A comparison of geometric means of clinical and environmental strains of $C$. gattii and $C$. neoformans was not found statistically significant using student ' $t$ ' test ( $\mathrm{p}$ value $>0.05 \mathrm{NS}$ ). Though less, the antifungal data obtained in this study suggests that primary resistance among environmental and clinical isolates of C. neoformans and C. gattii against tested antifungal was present and $C$. gattii comparatively was less susceptible than $C$. neoformans var. grubii isolates to fluconazole than to itraconazole and ketoconazole. A continuous surveillance of antifungal susceptibility of clinical and environmental isolates of $C$. neoformans and C. gattii is desirable to monitor the emergence of any resistant strains for better management of cryptococcosis patients.
\end{abstract}

Key words: Cryptococcus neoformans, Cryptococcus gattii, minimum inhibitory concentration, azoles, Central India.

\section{Introduction}

Cryptococcus neoformans (Serotype A, D, AD) and C. gattii (Serotype B and C) are opportunistic fungal pathogens that cause cryptococcosis predominantly in immunocompromised patients with AIDS, and also in immunocompromised patients with the underlying predisposing factors, such as haematological malignancies and organ transplantation (Mitchell and Perfect, 1995). Epidemiologically these species differ from each other mainly in geographic distribution, natural habitat, host infectivity and genetics (Casadevall and Perfect, 1998; Kwon-Chung and Varma, 2006). On the basis of molecular studies $C$. neoformans and $C$. gattii have been classified into several distinct genotypes.

Major antifungals available for therapy of cryptococcosis are limited to amphotericin B, 5 - flurocytosine and fluconazole. However, side effects associated with amphotericin-B and flurocytosine restrict their use. Azoles, on the other hand, offer a safer and efficacious option. Yet, one major concern with azole use has been the possible emergence of clinical resistance (Friese et al., 2001). Clinical resistance may be the result of infection with a resistant strain, or a relapse of infection due to natural selective pressure exerted on the pathogen by routine, inappropriate or excessive use of antimicrobial drugs are major factors in

Send correspondence to S.R. Nawange. Centre for Medical Mycology, Fungal Disease Diagnostic and Research Center, SRDTHFD L-3/1Kachnar City Lamti Marotal Near Kachnar Club Jabalpur (M.P.), 482002 Madhya Pradesh, India. E-mail: sr.nawange@gmail.com, sr_nawange@yahoo.com. 
the development of antimicrobial resistance (Archibald et al., 2004). In tropical developing countries, availability of drugs without prescription, sub-optimal therapeutic regimes, blind empirical prescribing practices that are not epidemiologically directed and lack of laboratory capacity or skilled personnel for susceptibility testing contribute to the antimicrobial resistance (Shears, 2001).

Although numerous studies have examined bacterial and mycobacterial resistance in tropics, less is known about the susceptibility profiles of medically important fungi to antifungal drugs (Davey et al., 1998; Pfaller et al., 1998; Pfaller et al., 1999;). In developing countries like India, because of limited resources or cost restrictions, the continuous surveillance for resistance to available antifungal drugs treatment is essential for appropriate patient care and improved patient's outcome.

The purpose of the present investigation was to analyse the in vitro susceptibilities of clinical and environmental isolates of C. neoformans and C. gattii to three azole antifungal drugs. The reference micro-dilution method (NCCLS-M27A) proposed by the National Committee for Clinical Laboratory Standards (presently CLSI-Clinical and Laboratory Standards Institute) was used for susceptibility testing.

\section{Materials and Methods}

\section{Fungal strains}

A total of 63 Cryptococcus isolates was used, in the study of which 9 were recovered from blood, urine, sputum and cerebrospinal fluid of HIV +ve patients. Out of these 9 clinical isolates, 8 were C. neoformans (Serotype A) and 1 was $C$. gattii. There were 54 environmental isolates, 50 were $C$. neoformans (Serotype A) and 4 were isolates of $C$. gattii. These isolates were isolated from the trunk hollows of (Tamarindus indica, Mangifera indica and Syzygium cumini) living trees in Jabalpur, Madhya Pradesh in Central India. These isolates were isolated and cultured over a period of seven years at Jabalpur city (Nawange et al., 2006; Grover et al., 2007; Nawange et al., 2011). For identification, the isolates were grown on niger seed agar medium for developing characteristic brown pigment. Physiological characteristics were determined as per Kwon-Chung and Bennett (Kwon-Chung and Bennett, 1992). Confirmation of $C$. gattii isolates was done by their ability to grow on canavanine glycine bromothymol blue medium, which was marked by a change in colour of the medium from greenish yellow to blue. Serotyping was done by crypto check kit. (Iatron laboratory Inc. Tokyo, Japan).

\section{Minimum inhibitory concentration (MIC) determination}

Antifungal susceptibilities were assessed using broth micro-dilution method of NCCLS/CLSI (National Committee for Clinical Laboratory Standards) M27-A guide- lines. (NCCLS/CLSI-M27A). There were $58 \quad C$. neoformans and 5 C. gattii (environmental and clinical) strains. The MIC was determined for the three commonly used azoles (fluconazole, ketoconazole, itraconazole). A serial dilution was made from the stock solution of the antifungal agents to have final concentration ranges of 0.03-64 $\mu \mathrm{g} / \mathrm{mL}$ for ketoconazole, fluconazole and itraconazole. The following antifungal drugs were used as assay powders: fluconazole (Flustan ${ }^{\mathrm{TM}}$; Dr. Reddy's Lab. Ltd.) ${ }^{\mathrm{TM}}$ - trademark under registration, itraconazole (Candistat; E Merck India Ltd.; Licensed user of T.M.), ketoconazole (Nizral-Johnson and Johnson Ethnor).

The yeast inocula were adjusted to a concentration of $0.5 \times 10^{3}-2.5 \times 10^{3} \mathrm{cfu} / \mathrm{mL}$ in RPMI medium as measured by spectrophotometer, and an aliquot of $0.1 \mathrm{~mL}$ was added to each well containing various concentrations of antifungal drugs. These plates were incubated at $35^{\circ} \mathrm{C}$ in air ambient incubator with positive (drug free well) and negative (broth well) control. End-points were read visually after 72 hours; the MIC's of ketoconazole, itraconazole and fluconazole were defined as the lowest concentration at which there was $50 \%$ inhibition of growth (i.e. slightly hazy) compared with that of drug free controls (NCCLS/CLSI M27-A). Interpretative break-points are as follows: Fluconazole $-\leq 8 \mu \mathrm{g} / \mathrm{mL}$ - susceptible, $16-32 \mu \mathrm{g} / \mathrm{mL}$ - intermediate, $\geq 64 \mu \mathrm{g} / \mathrm{mL}$ - resistant. Itraconazole- $\leq 0.125 \mu \mathrm{g} / \mathrm{mL}$ - susceptible, $0.25-0.5 \mu \mathrm{g} / \mathrm{mL}$ - intermediate, $\geq 1 \mu \mathrm{g} / \mathrm{mL}$ - resistant. Ketoconazole- $0.0625 \mu \mathrm{g} / \mathrm{mL}$ - susceptible, $\geq 0.125 \mu \mathrm{g} / \mathrm{mL}$ - resistant. The results were tabulated and analyzed with the version 5.5 of the software WHONET.

\section{Quality control strains}

Quality control and reference strains incorporated during every testing batch of broth micro-dilution were Candida albicans-ATCC 90028, C. tropicalis-ATCC-750 and C. glabrata-90030. The MICs of these strains were compared with the published control limits and used to guide antifungal susceptibility testing and validation according to National Committee for Clinical Laboratory Standards (presently CLSI) guidelines.

Clinically relevant break points for azoles were not available for $C$. neoformans, hence tentative break points available for $C$. albicans have been used for interpretation. (Pfaller et al., 1995; Rex et al., 1996; Rodriquez-Tudela et al., 1995).

\section{Statistical analysis}

The Chi-square test was applied to find significance between number of resistant $C$. neoformans and C. gattii strains for all the three azoles (fluconazole, itraconazole and ketoconazole). Fisher's exact $p$ value was calculated when number of isolates was less. Student ' $t$ ' test was applied to find the level of significance between clinical vs. environmental $C$. neoformans and $C$. gattii strains. 


\section{Results}

Table 1 shows the MIC results of fluconazole drug for 58 C. neoformans. The results revealed that $8.6 \%$ were resistant, $31.1 \%$ were intermediately susceptible, $60.3 \%$ were susceptible, the MIC50 was $8 \mu \mathrm{g} / \mathrm{mL}$, the MIC90 was 32 $\mu \mathrm{g} / \mathrm{mL}$, geometric mean was $6.93 \mu \mathrm{g} / \mathrm{mL}$, and MIC range was $0.063-64 \mu \mathrm{g} / \mathrm{mL}$. The MIC results for $C$. gattii (5) strains were as follows: $40 \%$ were resistant, $20 \%$ were intermediately susceptible, $40 \%$ were susceptible, the MIC50 was $16 \mu \mathrm{g} / \mathrm{mL}$ and the MIC90 $64 \mu \mathrm{g} / \mathrm{mL}$, geometric mean was $13.93 \mu \mathrm{g} / \mathrm{mL}$ and the MIC range was $2-64 \mu \mathrm{g} / \mathrm{mL}$.

The MIC results for itraconazole for $58 \mathrm{C}$. neoformans strains exhibited that $5.2 \%$ were resistant, $24.1 \%$ were intermediately susceptible, $70.7 \%$ susceptible, 0.125 was the MIC50 $\mu \mathrm{g} / \mathrm{mL}$ and the MIC90 $0.5 \mu \mathrm{g} / \mathrm{mL}$. The geometric mean was $0.124 \mu \mathrm{g} / \mathrm{mL}$ and MIC range $0.03-1 \mu \mathrm{g} / \mathrm{mL}$. The MIC values for C. gattii (5) strains against itraconazole showed no resistance and $40 \%$ were intermediately susceptible. However, $60 \%$ were susceptible, $0.125 \mu \mathrm{g} / \mathrm{mL}$ was the MIC50, the MIC90 was $0.5 \mu \mathrm{g} / \mathrm{mL}$, geometric mean was $0.125 \mu \mathrm{g} / \mathrm{mL}$ and the MIC range was $0.03-0.5 \mu \mathrm{g} / \mathrm{mL}$. The MIC results for drug ketoconazole for 58 C. neoformans strains exhibited $6.9 \%$ resistance, $55.2 \%$ were intermediately susceptible, $37.9 \%$ were susceptible, the MIC50 was $0.064 \mu \mathrm{g} / \mathrm{mL}$, the MIC90 was $0.064 \mu \mathrm{g} / \mathrm{mL}$, geometric mean was $0.051 \mu \mathrm{g} / \mathrm{mL}$, the MIC range was $0.03-0.25 \mu \mathrm{g} / \mathrm{mL}$. The MIC results of $C$. gattii (5) strains for ketoconazole exhibited 20\% resistance, $20 \%$ were intermediately susceptible, $60 \%$ were susceptible, the MIC50 was $0.032 \mu \mathrm{g} / \mathrm{mL}$, the MIC90 was $0.125 \mu \mathrm{g} / \mathrm{mL}$, geometric mean was $0.047 \mu \mathrm{g} / \mathrm{mL}$ and the MIC range was $0.03-0.125 \mu \mathrm{g} / \mathrm{mL}$.

Table 2 shows a comparative data of geometric means of $C$. gattii clinical (1) and environmental strains (4). The geometric mean of clinical C. gattii strains for fluconazole

Table 1 - Antifungal susceptibility results of three azoles against 58 C. neoformans and 5 C. gattii isolates in Jabalpur Madhya Pradesh Centaral India.

\begin{tabular}{|c|c|c|c|c|c|c|c|c|}
\hline \multirow[t]{2}{*}{ Antifungal agent \& organism } & \multirow[t]{2}{*}{ No. Tested } & \multicolumn{7}{|c|}{$\operatorname{MIC}(\mu \mathrm{g} / \mathrm{mL})$} \\
\hline & & $\% \mathrm{R}$ & $\% \mathrm{I}-\mathrm{S}$ & $\% \mathrm{~S}$ & MIC 50 & MIC90 & Geom. Mean & MIC Range \\
\hline \multicolumn{9}{|l|}{ Fluconazole } \\
\hline C. neoformans & 58 & 8.6 & 31.1 & 60.3 & 8 & 32 & 6.93 & $0.063-64$ \\
\hline C. gattii & 5 & $40^{*}$ & 20 & 40 & 16 & 64 & 13.93 & $2-64$ \\
\hline \multicolumn{9}{|l|}{ Itraconazole } \\
\hline C. neoformans & 58 & 5.2 & 24.1 & 70.7 & 0.125 & 0.5 & 0.124 & $0.03-1$ \\
\hline C. gattii & 5 & $0 \mathrm{NS}$ & 40 & 60 & 0.125 & 0.5 & 0.125 & $0.03-0.5$ \\
\hline \multicolumn{9}{|l|}{ Ketoconazole } \\
\hline C. neoformans & 58 & 6.9 & 55.2 & 37.9 & 0.064 & 0.064 & 0.051 & $0.03-0.25$ \\
\hline C. gattii & 5 & $20 \mathrm{NS}$ & 20 & 60 & 0.032 & 0.125 & 0.047 & $0.03-0.125$ \\
\hline
\end{tabular}

$* \chi^{2}=4.589,(\mathrm{p}=0.01609), \mathrm{p}<0.05 *$ (Significant) and fisher's exact $\mathrm{p}$ value $=0.09077$ (NS).

NS - Not significant; \% R - Percent resistant; \% I-S - Percent intermediate susceptible; \% S - Percent susceptible.

Table 2 - A Comparisons of geometric means of clinical and environmental isolates of C. gattii and C. neoformans isolates in Jabalpur Madhya Pradesh Central India.

\begin{tabular}{|c|c|c|c|c|c|}
\hline Organism & TYPE & & FLU & ITR & KET \\
\hline \multirow[t]{3}{*}{$C g(5)$} & Clin. (1) & Geometric Mean & 16.00 & 0.125 & 0.03 \\
\hline & Env. (4) & Geometric Mean & 13.45 & 0.124 & 0.05 \\
\hline & & ' $\mathrm{t}$ ' test $\mathrm{p}$ value & $\mathrm{p}>0.05$ & $\mathrm{p}>0.05$ & $\mathrm{p}>0.05$ \\
\hline \multirow[t]{3}{*}{ Cn (58) } & Clin. (8) & Geometric Mean & 8.72 & 0.210 & 0.06 \\
\hline & Env. (50) & Geometric Mean & 6.68 & 0.114 & 0.049 \\
\hline & & ' $t$ ' test $p$ value & $\mathrm{p}>0.05$ & $\mathrm{p}>0.05$ & $\mathrm{p}>0.05$ \\
\hline \multirow[t]{3}{*}{ Total (63) } & Clin. (9) & Geometric Mean & 9.33 & 0.198 & 0.06 \\
\hline & Env. (54) & Geometric Mean & 7.04 & 0.115 & 0.049 \\
\hline & & ' $\mathrm{t}$ ' test $\mathrm{p}$ value & $p>0.05$ & $p>0.05$ & $p>0.05$ \\
\hline
\end{tabular}

Cg - Cryptococcus gattii (B); Cn - Cryptococcus neoformans (A/D); Flu - Fluconazole; Itra - Itraconazole; Ket o -Ketoconazole; Clin. - Clinical; Env. Environmental. 
was $16 \mu \mathrm{g} / \mathrm{mL}$, itraconazole $0.125 \mu \mathrm{g} / \mathrm{mL}$ and ketoconazole $0.03 \mu \mathrm{g} / \mathrm{mL}$. Likewise, the geometric means of environmental isolates for fluconazole was $13.45 \mu \mathrm{g} / \mathrm{mL}$, itraconazole $0.124 \mu \mathrm{g} / \mathrm{mL}$ and for ketoconazole, it was $0.05 \mu \mathrm{g} / \mathrm{mL}$. On comparison, the geometric means for all the three drugs was not found statistically significant for both clinical and environmental strains.

Likewise, for C. neoformans clinical (8) strains, the geometric mean for fluconazole was $8.72 \mu \mathrm{g} / \mathrm{mL}$, for itraconazole was $0.21 \mu \mathrm{g} / \mathrm{mL}$ and for ketoconazole, it was $0.06 \mu \mathrm{g} / \mathrm{mL}$. For C. neoformans environmental isolates (50), the geometric mean for fluconazole was $6.68 \mu \mathrm{g} / \mathrm{mL}$, for itraconazole, it was $0.114 \mu \mathrm{g} / \mathrm{mL}$, and for ketoconazole, $0.049 \mu \mathrm{g} / \mathrm{mL}$. In comparison, the geometric means for all the three drugs was not found statistically significant for both clinical and environmental strains.

The MIC geometric means of clinical strains (9) for fluconazole was 9.33 , for itraconazole was 0.198 , and for drug ketoconazole was 0.06 . Similarly, the environmental strains (54) had a geometric mean of 7.04 for fluconazole, 0.115 for itraconazole and for drug ketoconazole 0.049 respectively. The comparison of geometric means for all the three drugs was not found statistically significant for total clinical (9) and environmental (54) strains.

Table 3, categorizes the sources of strains, the abundance of C. neoformans and C. gattii, with their mean MIC values and the MIC range of fluconazole, itraconazole and ketoconazole drugs. There were 54 environmental strains, out of which 50 were $C$. neoformans and 4 were $C$. gattii.

There were 6 C. neoformans strains isolated from soil contaminated by house hold garbage; $12.66 \mu \mathrm{g} / \mathrm{mL}$ was the mean MIC value for the drug fluconazole and $4-16 \mu \mathrm{g} / \mathrm{mL}$ was the range. The mean MIC for itraconazole was $0.22 \mu \mathrm{g} / \mathrm{mL}$ and $0.03-1 \mu \mathrm{g} / \mathrm{mL}$ was the MIC range. The mean MIC for the drug ketoconazole was $0.08 \mu \mathrm{g} / \mathrm{mL}$ and the MIC range was $0.03-0.25 \mu \mathrm{g} / \mathrm{mL}$. There were $4 C$. neoformans strains isolated from soil contaminated by hospital waste; $18.5 \mu \mathrm{g} / \mathrm{mL}$ was the mean MIC and $2-32 \mu \mathrm{g} / \mathrm{mL}$ was the range for the drug fluconazole. The mean MIC value for the drug itraconazole was $0.06 \mu \mathrm{g} / \mathrm{mL}$ and $0.03-0.125 \mu \mathrm{g} / \mathrm{mL}$ was the range. The mean MIC for the drug ketoconazole was $0.03 \mu \mathrm{g} / \mathrm{mL}$. There were $2 C$. neoformans strains isolated from soil soaked with human urine; $4.25 \mu \mathrm{g} / \mathrm{mL}$ was the mean MIC for the drug fluconazole and $0.5-8 \mu \mathrm{g} / \mathrm{mL}$ was the MIC range; $0.125 \mu \mathrm{g} / \mathrm{mL}$ was the mean MIC value for the drug itraconazole; $0.045 \mu \mathrm{g} / \mathrm{mL}$ was the mean MIC for the drug ketoconazole and the range was $0.03-0.06 \mu \mathrm{g} / \mathrm{mL}$. There were $8 C$. neoformans strains collected from soil contaminated by pigeon droppings; $25.75 \mu \mathrm{g} / \mathrm{mL}$ was the mean MIC value for the drug fluconazole and $2-64 \mu \mathrm{g} / \mathrm{mL}$ was the range for this drug. The mean MIC for the drug itraconazole was
$0.16 \mu \mathrm{g} / \mathrm{mL}$ and $0.03-0.125 \mu \mathrm{g} / \mathrm{mL}$ was the range. The mean MIC value for the drug ketoconazole was $0.085 \mu \mathrm{g} / \mathrm{mL}$ and $0.03-0.06 \mu \mathrm{g} / \mathrm{mL}$ was the range for this drug. There were 6 strains of $C$. neoformans isolated from soil contaminated by other bird excreta; $14.01 \mu \mathrm{g} / \mathrm{mL}$ was the mean MIC value for fluconazole and $0.063-32 \mu \mathrm{g} / \mathrm{mL}$ was the MIC range for this drug. The mean MIC for the drug itraconazole was $0.29 \mu \mathrm{g} / \mathrm{mL}$ and $0.032-0.125 \mu \mathrm{g} / \mathrm{mL}$ was the range for this drug. The mean MIC value for the drug ketoconazole was $0.06 \mu \mathrm{g} / \mathrm{mL}$. There were $11 C$. neoformans strains isolated from pigeon excreta; $20.47 \mu \mathrm{g} / \mathrm{mL}$ was the mean MIC value for the drug fluconazole with the MIC range of $0.125-64 \mu \mathrm{g} / \mathrm{mL}$ for this drug. The mean MIC value for the drug itraconazole was $0.15 \mu \mathrm{g} / \mathrm{mL}$ and the range was $0.06-0.25 \mu \mathrm{g} / \mathrm{mL}$. The mean MIC value for the drug ketoconazole was $0.052 \mu \mathrm{g} / \mathrm{mL}$ and $0.03-0.06 \mu \mathrm{g} / \mathrm{mL}$ was the range. There were $3 C$. gattii strains isolated from tree trunk hollows from Tamarindus indica; $23.3 \mu \mathrm{g} / \mathrm{mL}$ was the mean MIC for the drug fluconazole and 2-64 $\mu \mathrm{g} / \mathrm{mL}$ was the range. The mean MIC value for itraconazole was $0.34 \mu \mathrm{g} / \mathrm{mL}$ and $0.03-0.5 \mu \mathrm{g} / \mathrm{mL}$ the range for this drug. The mean MIC value for ketoconazole was $0.072 \mu \mathrm{g} / \mathrm{mL}$ and $0.03-0.125 \mu \mathrm{g} / \mathrm{mL}$ was the range for this drug. There were 2 C. neoformans strains isolated from tree trunk hollows of Mangifera indica; $8.25 \mu \mathrm{g} / \mathrm{mL}$ was the mean MIC for fluconazole and $0.5-16 \mu \mathrm{g} / \mathrm{mL}$ was the range for this drug. The mean MIC for itraconazole was $0.155 \mu \mathrm{g} / \mathrm{mL}$ and $0.06-0.25 \mu \mathrm{g} / \mathrm{mL}$ was the range for this drug. The mean MIC range for ketoconazole was $0.06 \mu \mathrm{g} / \mathrm{mL}$. There were 4 strains isolated from tree trunk hollow of Syzygium cumini; 1 was $C$. gattii and 3 were C. neoformans; the mean MIC values for C. gattii strains for the three drugs fluconazole, itraconazole and ketoconazole were $64,0.032$, and $0.032 \mu \mathrm{g} / \mathrm{mL}$ respectively. The mean MIC value for C. neoformans strains, for fluconazole was $3.67 \mu \mathrm{g} / \mathrm{mL}$ and $1-8 \mu \mathrm{g} / \mathrm{mL}$ was the range for this drug. The mean MIC for drug itraconazole was $0.072 \mu \mathrm{g} / \mathrm{mL}$ and $0.03-0.125 \mu \mathrm{g} / \mathrm{mL}$ was the range. The mean MIC for the drug ketoconazole was $0.05 \mu \mathrm{g} / \mathrm{mL}$ and the range was $0.03-0.06 \mu \mathrm{g} / \mathrm{mL}$. There were 4 strains isolated from Eucalyptus spp.; $10.25 \mu \mathrm{g} / \mathrm{mL}$ was the mean MIC for the drug fluconazole and $1-32 \mu \mathrm{g} / \mathrm{mL}$ was the range. The mean MIC for the drug itraconazole was $0.59 \mu \mathrm{g} / \mathrm{mL}$ and $1-0.25 \mu \mathrm{g} / \mathrm{mL}$ was the range for this drug. The mean MIC value for the drug ketoconazole was $0.06 \mu \mathrm{g} / \mathrm{mL}$. There was only a single $C$. neoformans strain isolated from the soil contaminated by bird droppings; $8 \mu \mathrm{g} / \mathrm{mL}$ was the mean MIC for fluconazole, $0.125 \mu \mathrm{g} / \mathrm{mL}$ was the mean MIC for itraconazole and $0.03 \mu \mathrm{g} / \mathrm{mL}$ was the mean MIC for the drug ketoconazole. There were $3 C$. neoformans strains procured from the soil contaminated in poultry farm; $4.67 \mu \mathrm{g} / \mathrm{mL}$ was the mean MIC for fluco- 


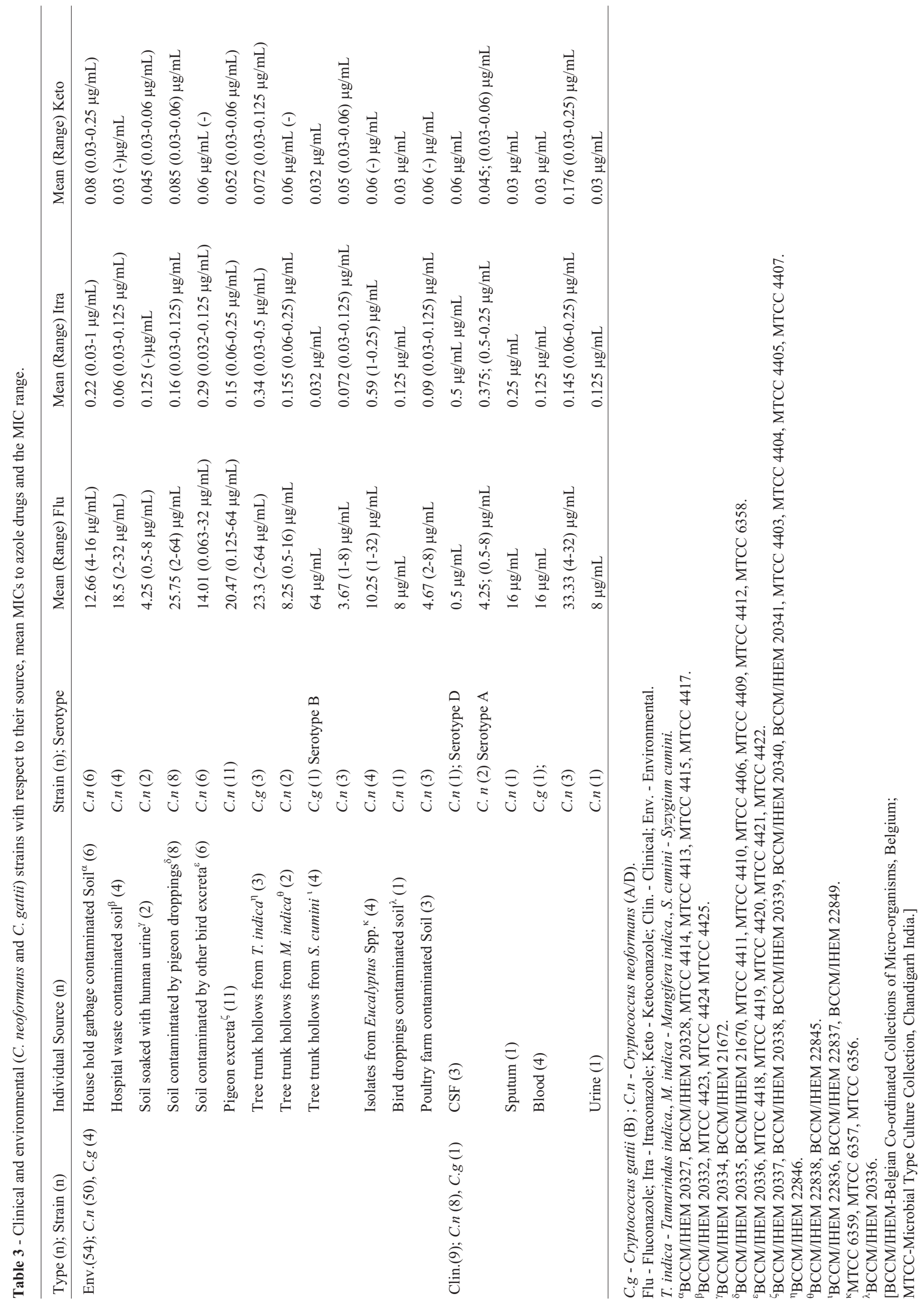


nazole and $2-8 \mu \mathrm{g} / \mathrm{mL}$ was the range. The mean $\mathrm{MIC}$ for the drug itraconazole was $0.09 \mu \mathrm{g} / \mathrm{mL}$ and $0.03-0.125 \mu \mathrm{g} / \mathrm{mL}$ was the range. The mean MIC for the drug ketoconazole was $0.06 \mu \mathrm{g} / \mathrm{mL}$.

There were 9 clinical strains out of which 8 were $C$. neoformans and 1 was $C$. gattii. There were $3 C$. neoformans strains isolated from cerebrospinal fluid, in which 1 strain was serotype D; the MIC for the three drugs fluconazole, itraconazole and ketoconazole were $0.5 \mu \mathrm{g} / \mathrm{mL}, 0.5 \mu \mathrm{g} / \mathrm{mL}$ and $0.06 \mu \mathrm{g} / \mathrm{mL}$ respectively. The other 2 strains from cerebrospinal fluid were serotype A; the mean MIC for fluconazole was $4.25 \mu \mathrm{g} / \mathrm{mL}$ and the range was $0.5-8 \mu \mathrm{g} / \mathrm{mL}$. The mean MIC for itraconazole was $0.375 \mu \mathrm{g} / \mathrm{mL}$ and the MIC range for this drug was $0.5-0.25 \mu \mathrm{g} / \mathrm{mL}$. The mean MIC for the drug ketoconazole was $0.045 \mu \mathrm{g} / \mathrm{mL}$ and the MIC range was $0.03-0.06 \mu \mathrm{g} / \mathrm{mL}$. There was a single $C$. neoformans strain isolated from sputum the MIC for the three drugs were 16, 0.25 and $0.03 \mu \mathrm{g} / \mathrm{mL}$ respectively. There were 4 strains isolated from blood (1 C. gattii and $3 C$. neoformans). The single $C$. gattii strain isolated from blood had the MIC values for the three drugs as follows: $16 \mu \mathrm{g} / \mathrm{mL}, 0.125 \mu \mathrm{g} / \mathrm{mL}$ and $0.03 \mu \mathrm{g} / \mathrm{mL}$ respectively. The mean MIC values for $3 C$. neoformans strains isolated from blood were $33.33 \mu \mathrm{g} / \mathrm{mL}$; the MIC range was $4-32 \mu \mathrm{g} / \mathrm{mL}$ for drug fluconazole, $0.145 \mu \mathrm{g} / \mathrm{mL}$ was the mean MIC for the drug itraconazole with a range of $0.06-0.25 \mu \mathrm{g} / \mathrm{mL}$ and $0.176 \mu \mathrm{g} / \mathrm{mL}$ was the mean MIC for the drug ketoconazole with range of $0.03-0.25 \mu \mathrm{g} / \mathrm{mL}$.

There was only one $C$. neoformans strain isolated from urine. The MIC values for fluconazole, itraconazole and ketoconazole drugs for this isolate were 8, 0.125 and $0.03 \mu \mathrm{g} / \mathrm{mL}$ respectively.

\section{Statistical results}

Antifungal susceptibility results of three azoles against 58 C. neoformans and 5 C. gattii isolates have been summarized in Table 1. C. gattii showed higher percentage of resistance (40\%) compared with that of $C$. neoformans for fluconazole and statistically this difference was significant $\left(\chi^{2}=4.589 ; \mathrm{p}=0.01609^{*}\right)$, while considering fisher's exact $\mathrm{p}$ value $=0.09077$, showed non-significance.

The total number of resistant cases for itraconazole and ketoconazole did not show any significant difference compared to C. neoformans and C. gattii.

A comparison of geometric means of clinical and environmental isolates of $C$. gattii and $C$. neoformans shown in Table 2 was not statistically significant using student ' $t$ ' test ( $p$ value $>0.05 \mathrm{NS}$ ). Comparison of clinical (9) vs. environmental (54) isolates was also not statistically significant using student ' $\mathrm{t}$ ' test ( $\mathrm{p}$ value $>0.05 \mathrm{NS}$ ).

\section{Discussion}

Review of literature on the subject revealed that in-vitro susceptibilities of $C$. neoformans and $C$. gattii strains to antifungal drugs have been studied by a number of investigators in India and abroad (Archibald et al., 2004; Chowdhary et al., 2011; Govender et al., 2011; Khan et al., 2009; Sar et al., 2004; Souza et al., 2005). However, few studies on the antifungal susceptibilities of clinical and environmental strains of $C$. neoformans and $C$. gattii have been reported (Chowdhary et al., 2011; Franzot and Hamdan, 1996; Souza et al., 2005). This study is noteworthy for documenting the antifungal susceptibility profiles of environmental and clinical isolates of $C$. neoformans and $C$. gattii against fluconazole, itraconazole and ketoconazole in Central India employing micro-dilution method of CLSI/NCCLS-M27A guidelines (NCCLS-M27A). Earlier studies from India like that of Khan et al. (2007) reported antifungal susceptibility profiles of clinical and environmental isolates of C. neoformans (serotype A) and C. gattii (serotype B) against amphotericin B, fluconazole, itraconazole, voriconazole and 5-flurocytosine from northeastern India. Their data on geometric mean of MICs revealed that $C$. gattii was significantly less susceptible than C. neoformans to fluconazole, itraconazole and voriconazole $(\mathrm{p}<0.0001)$. In the same study MIC90 of $C$. gattii was two fold higher than that of $C$. neoformans for fluconazole, itraconazole and voriconazole. In this study, a comparison of the geometric mean of MIC revealed that environmental isolates of $C$. neoformans were less susceptible than environmental isolates of $C$. gattii to fluconazole. There was also no significant difference found between the antifungal susceptibilities profiles of clinical and environmental isolates of $C$. neoformans and $C$. gattii $(\mathrm{p}<0.05)$. On the contrary, Chowdhary et al. (2011) reported that environmental $C$. neoformans variety grubii were significantly less susceptible to fluconazole, itraconazole than the clinical isolates. However, Souza et al. (2005) reported that the MIC results obtained from their clinical and environmental isolates showed similar pattern of susceptibility and no resistance was found. Earlier similar results were obtained from Brazil (Franzot and Hamdan, 1996).

The present study demonstrated that susceptibilities of C. neoformans var. grubii and C. gattii differed, with $C$. gattii isolates showing high resistance for fluconazole and ketoconazole than those of $C$. neoformans var. grubii. This is in conformity with several earlier reports (Chowdhary et al., 2011; Fernandes et al., 2003; Gomez-Lopez et al., 2008; Trilles et al., 2004). However, contrary results showing no such differences in antifungal susceptibilities of the two species have been reported by some workers (Morgan et al., 2006; Tay et al., 2006; Thompson et al., 2009). This could be due to a possible lack of uniformity in the methodologies used by different workers. Chowdhary et al. (2011) reported lower susceptibility of environmental isolates of C. neoformans var. grubii to fluconazole and itraconazole 
than their clinical isolates. This is contrary to our results which exhibited that differences in the clinical and environmental isolates of $C$. neoformans var. grubii was not statistically significant. Thus, we corroborate the findings of some investigators who found that antifungal susceptibility was not related to the clinical or environmental origin of strains. (Franzot and Hamdan, 1996; Moraes et al., 2003; Trilles et al., 2004).

Interestingly, our results revealed that environmental isolates of $C$. neoformans var. grubii from soil contaminated by pigeon excreta, pigeon droppings and from the trunk hollows of Tamarindus indica tree exhibited lower susceptibility to fluconazole compared to other environmental sources and clinical isolates. This is quite similar to the finding of Chowdhary et al. (2011). However, on the contrary, the findings of some other investigators showed that antifungal susceptibility was not related to the clinical or environmental origin of strains (Franzot and Hamdan, 1996; Moraes et al., 2003; Trilles et al., 2004). In the present study, we have also found a solitary isolate of $C$. gattii (serotype B) from the trunk hollow of $S$. cumini tree to be resistant to fluconazole (MIC $64 \mu \mathrm{g} / \mathrm{mL}$ ). Similarly, Khan et al. (2009) and Chowdhary et al. (2011) have also reported that $C$. gattii isolates were significantly less susceptible than those of $C$. neoformans var. grubii to fluconazole.

Dutta et al. (2003) assessed fluconazole and itraconazole susceptibilities of clinical isolates of $C$. neoformans in India. They reported that susceptibilities to fluconazole and itraconazole were $84.1 \%$ and $93.2 \%$ respectively. MIC50 and MIC90 values for fluconazole were 4 and $16 \mu \mathrm{g} / \mathrm{mL}$ respectively. In the present study, we found $60.3 \%$ and $70.7 \%$ susceptibilities of environmental isolates of $C$. neoformans to fluconazole and itraconazole respectively. In our case, MIC 50 and MIC 90 values for fluconazole were 8 and $32 \mathrm{mg} / \mathrm{L}$. It is just double the values reported by Dutta et al. (2003) for clinical isolates of $C$. neoformans for fluconazole. Similarly, MIC50 value for itraconazole in the present study was $0.125 \mu \mathrm{g} / \mathrm{mL}$, much higher than $0.032 \mu \mathrm{g} / \mathrm{mL}$ reported by Dutta et al. (2003). Khan et al. (2007) reported $4 \mu \mathrm{g} / \mathrm{mL}$ as MIC90 for $C$. neoformans isolates from decayed wood of trunk hollows against fluconazole. On the contrary, our environmental isolates exhibited much higher values $32 \mu \mathrm{g} / \mathrm{mL}$ MIC90 value for fluconazole; likewise for itraconazole our MIC90 value was $0.05 \mu \mathrm{g} / \mathrm{mL}$ much lower $(0.094 \mu \mathrm{g} / \mathrm{mL})$ reported by Khan et al. (2007) respectively. Interestingly, our value of MIC90 for ketoconazole was similar, i.e. $0.064 \mu \mathrm{g} / \mathrm{mL}$ to that of Khan et al. (2007).

We conclude, that the susceptibilities of $C$. neoformans and C. gattii isolates differed, with C. gattii strains showing higher resistance percentages (for fluconazole and ketoconazole drugs) than those of C. neoformans.
Trpkovic et al. (2012) reported lowest activity of fluconazole in vitro (48.4\% susceptibility). Our results also indicate lowest activity of fluconazole for $C$. gattii strains (40\%), however lowest susceptibility of $37.9 \%$ was observed in case of $C$. neoformans strains for the drug ketoconazole.

Tangwattanachuleeporn et al. (2013) analyzed the prevalence and antifungal susceptibilities of $C$. neoformans isolated from pigeon excreta from Eastern Thailand. This group studied 50 pigeon excreta samples; $100 \%$ of $C$. neoformans isolated from pigeon excreta were of serotype A. Tangwattanachuleeporn et al. (2013) also observed decreased susceptibility towards fluconazole; still all strains tested were sensitive towards fluconazole and itraconazole. However, in the present study we observed $8.6 \%$ resistance for $C$. neoformans and $40 \%$ for C. gattii strains, while $5.2 \%$ resistance was observed for the drug itraconazole for $C$. neoformans strains.

Antifungal susceptibilities and genotypes of clinical isolates were analyzed in Brazil by Matos et al. (2012). Their study revealed resistance to fluconazole $(4.8 \%)$, which is lower than our results of $8.6 \%$ resistance in $C$. neoformans and $40 \%$ in case of $C$. gattii for the drug fluconazole. This study also revealed the high percentage of $C$. gattii strains belonged to VGII genotype and its low susceptibility to antifungal agents is worth considering.

The low susceptibility of VGII genotype was also shown by Trilles et al. (2012). In their study geometric means for the drugs fluconazole, itraconazole and ketoconazole for VGII genotype were $6.08,0.15$ and 0.06 respectively. Our results revealed geometric means for these three drugs for $C$. neoformans vs. C. gattii strains were as follows: 6.93 vs. $13.93,0.124$ vs. 0.125 and 0.051 vs. 0.047 for fluconazole, itraconazole and ketoconazole respectively.

Favalessa et al. (2014) analyzed the molecular types and in-vitro antifungal susceptibilities of Cryptococcus spp. from patients in Mid west Brazil. Their MICs ranges for antifungal drugs were as follows fluconazole was $1-16 \mathrm{mg} / \mathrm{L}$, itraconazole was $0.25-0.12 \mathrm{mg} / \mathrm{L}$, while in the present study the MIC range for $C$. neoformans was $0.063-64 \mu \mathrm{g} / \mathrm{mL}$ and was $2-64 \mu \mathrm{g} / \mathrm{mL}$ for $C$. gattii for the drug fluconazole. The MIC range for the drug itraconazole was $0.03-1 \mu \mathrm{g} / \mathrm{mL}$ for $C$. neoformans and $0.03-0.5 \mu \mathrm{g} / \mathrm{mL}$ for $C$. gattii strains respectively. Favalessa et al. (2014) also concluded that the predominant genotype affecting HIVnegative individuals in Cuiaba is AFLP6/VGII.

The MIC results of our Central Indian strains are higher in comparison with other related national and international studies. Recent studies have highlighted that the genotypes and origin of $C$. neoformans and $C$. gattii had profound influence on their antifungal susceptibilities (Chong et al., 2010; Iqbal et al., 2010). In this present work, we were not able to work out the molecular types of the present strains. Hence, our next goal would be to determine 
these molecular types and to draw a valid conclusion about the same.

\section{Acknowledgments}

The authors wish to thank the Vice-Chancellor of $\mathrm{R}$. D. University for providing laboratory facilities and to the Director-General of Indian Council of Medical Research (ICMR), New Delhi for awarding Senior Research Fellowship and Post Doctoral Research Associateship for this work. We are also grateful to the Government of India, Ministry of Science and Technology, DST for awarding SERC FAST Track Scheme for Young Scientist to one of the author (S.R.N).

\section{References}

Archibald LK, Tuohy MJ, Wilson DA et al. (2004) Antifungal susceptibilities of Cryptococcus neoformans. Emerg Infect Dis 10:143-145.

Casadevall A, Perfect JR (1998) Cryptococcus neoformans. Washington DC: American Society for Microbiology.

Chong HS, Dagg R, Malik R et al. (2010) In vitro susceptibility of the yeast pathogen Cryptococcus to fluconazole and other azoles varies with molecular genotype. J Clin Microbiol 48:4115-4120.

Chowdhary A, Randhawa HS, Sundar G et al. (2011) In vitro antifungal susceptibility profiles and genotypes of 308 clinical and environmental isolates of Cryptococcus neoformans var. grubii and Cryptococcus gattii serotype B from northwestern India. J Med Microbiol 60:961-967.

Davey KG, Johnson EM, Holmes AD et al. (1998) In vitro susceptibility of $C$. neoformans isolates to Fluconazole and Itraconazole. Antimicrob Agents Chemother 42:217-220.

Dutta K, Jain N, Sethi S et al. (2003) Fluconazole and itraconazole susceptibility of clinical isolates of Cryptococcus neoformans at a tertiary care centre in India: a need for care. Antimicrob Agents Chemother 52:683-686.

Favalessa OC, de Paula DA, Dutra V et al. (2014) Molecular typing and in vitro antifungal susceptibility of Cryptococcus spp from patients in Midwest Brazil. J Infect Dev Ctries 8:1037-1043.

Fernandes de FL, Passos XS, Souza LK et al. (2003) In vitro susceptibility characteristics of Cryptococcus neoformans varieties from AIDS patients in Goiania, Brazil. Memórias do Instituto Oswaldo Cruz 98:839-841.

Franzot SP, Hamdan JS (1996) In vitro susceptibilities of clinical and environmental isolates of Cryptococcus neoformans to five antifungal drugs. Antimicrob Agents Chemother 40:822-824.

Friese G, Discher T, Fussle R et al. (2001) Development of azole resistance during fluconazole maintenance therapy for AIDS associated cryptococcal disease. AIDS 15:2344-2345.

Gomez-Lopez A, Zaragoza O, Martins DA et al. (2008) In vitro susceptibility of Cryptococcus gattii clinical isolates. Clin Microbiol Infect 14:727-730.

Govender NP, Patel J, WyK MV et al. (2011) Trends in Antifungal drug Susceptibility of Cryptococcus neoformans obtained through population based surveillance, South Africa, 2002-2003 and 2007-2008. Antimicrob Agents Chemother DOI: 10.1128/AAC.00048-11.
Grover N, Nawange SR, Naidu J et al. (2007) Ecological niche of Cryptococcus neoformans var. grubii and Cryptococcus gattii in decaying wood of trunk hollows of living trees in Jabalpur City of Central India. Mycopathol 164:159-170.

Iqbal N, De Bass EE, Wohrle R et al. (2010) Correlation of genotype and in-vitro susceptibilities of Cryptococcus gattii strains from the Pacific North west of the United States. J Clin Microbiol 48:539-544.

Khan ZU, Randhawa HS, Chehadeh W et al. (2009) Cryptococcus neoformans serotype A and Cryptococcus gattii serotype B isolates differ in their susceptibilities to fluconazole and voriconazole. Intern J Antimicro Agent 33:559-563.

Khan ZU, Randhawa HS, Kowshik T et al. (2007) Antifungal susceptibility of Cryptococcus neoformans and Cryptococcus gattii isolates from decayed wood of trunk hollows of Ficus religiosa and Syzygium cumini trees in north-western India. Antimicrob Agents Chemother 60:312-316.

Kwon-Chung KJ, Bennett JE (1992) Cryptococcus and Cryptococcosis. In: Kwon-Chung KJ, Bennett JE (eds) Medical Mycology, Philadelphia. Lea and Febiger, London, pp 397-446.

Kwon-Chung KJ, Varma SA (2006) Do major species concepts support one, two or more species within Cryptococcus neoformans? FEMS Yeast Res 6:574-577.

Matos CS, Andrade AS, Oliveira NS, Barros TF (2012). Microbiological characteristics of clinical isolates of Cryptococcus spp. in Bahia, Brazil: molecular types and antifungal susceptibilities. Eur J Clin Microbiol Infect Dis 31:1647-1652.

Mitchell TG, Perfect JR (1995) Cryptococcosis in the era of AIDS- 100 years after the discovery of Cryptococcus neoformans. Clin Microbiol Rev 8:515-518.

Moraes EM, Prímola NS, Hamdan JS (2003) Antifungal susceptibility of clinical and environmental isolates of Cryptococcus neoformans to four antifungal drugs determined by two techniques. Mycoses 46:164-168.

Morgan J, McCarthy KM, Gould S et al. (2006) Cryptococcus gattii infection: Characteristics and Epidemiology of cases identified in a South African Province with high HIV seroprevalence, 2002-2004. Clin Infect Dis 43:1077-1080.

National Committee for Clinical Laboratory Standards (1997) Reference method for broth dilution antifungal susceptibility testing of Yeasts. M27-A NCCLS, Wayne Pa, USA.

Nawange SR, Shakya K, Naidu J et al. (2006) Decayed wood inside trunk hollows of living trees of Tamarindus indica, Syzygium cumini and Mangifera indica as natural habitat of Cryptococcus neoformans and their Serotypes in Jabalpur city of Central India. Mycol Med 16:63-71.

Nawange SR, Singh SM, Naidu J et al. (2011) Serotype distribution of Cryptococcus neoformans and C. gattii in patients and in the environment of Jabalpur, a City of Madhya Pradesh in India. Asian J Microbiol Biotechnol Environ Sci 13:735-742.

Pfaller MA, Bale M, Buschelman B et al. (1995) Quality control guidelines for National Committee for Clinical Laboratory Standards recommended broth macrodilution testing of Amphotericin B, Fluconazole, and Flucytosine. J Clin Microbiol 33:1104-1107.

Pfaller MA, Zhang J, Messer SA et al. (1999) In vitro activities of voriconazole, fluconazole and itraconazole against 566 clinical isolates of Cryptococcus neoformans from the United 
States and Africa. Antimicrob Agents Chemother 43:167-171.

Pfaller MA, Zhang J, Messer SA et al. (1998) Molecular epidemiology and antifungal susceptibility of Cryptococcus neoformans isolates from Ugandan AIDS patients. Diag Microbiol Infect Dis 32:191-199.

Rex JH, Nelson PW, Lezane CM et al. (1996) Interpretation of trailing endpoints in antifungal susceptibility testing by National Committee for Clinical Laboratory Standards method. J Clin Microbiol 36:153-156.

Rodriguez-Tudela JL, Martinez-Suarez JV, Dronda F et al. (1995) Correlation of in-vitro susceptibility test results with clinical response: a study of azole therapy in AIDS patients. Antimicrob Agents Chemother 35:793-804.

Sar B, Monchy D, Vann M et al. (2004) Increasing in vitro resistance to fluconazole in Cryptococcus neoformans Cambodian isolates: April 2000 to March 2002. Antimicrob Agents Chemother 54:563-565.

Shears P (2001) Antibiotic resistance in the Tropics. Tran R Soc Trop Med Hyg 95:127-130.

Souza LKH, Fernandes OFL, Kobayashi CCBA et al. (2005) Antifungal susceptibilities of clinical and environmental isolates of Cryptococcus neoformans in Goiânia City Goiás Brazil. Rev Inst Med Trop Sao Paulo 47:253-256.

Tangwattanachuleeporn M, Somparn P, Poolpol K et al. (2013). Prevalence and antifungal susceptibility of Cryptococcus neoformans isolated from pigeon excreta in Chon Buri Province, Eastern Thailand. Med Mycol 54:303-307.

Tay ST, Tantay HT, Ng KP et al. (2006) In vitro susceptibilities of Malaysian clinical isolates of Cryptococcus neoformans var. grubii and Cryptococcus gattii to five antifungal drugs. Mycoses 49:324-330.

Thompson GR III, Wiederhold NP, Fothergill AW et al. (2009) Antifungal susceptibilities among different serotypes of Cryptococcus gattii and Cryptococcus neoformans. Antimicrob Agents Chemother 53:309-311.

Trilles L, Fernández-Torres B, Lazéra MS et al. (2004) In vitro antifungal susceptibility of Cryptococcus gattii. J Clin Microbiol 42:4815-4817.

Trilles L, Meyer W, Wanke B et al. (2012). Correlation of antifungal susceptibility and molecular type within the Cryptococcus neoformans/C. gattii species complex. Med Mycol 50:328-332.

Trpkovic A, Pekmezovic M, Barac A et al. (2012) In vitro antifungal activities of amphotericin B, 5-fluorocytosine, fluconazole and itraconazole against Cryptococcus neoformans isolated from cerebrospinal fluid and blood from patients in Serbia. Mycol Med 22:243-248.

WHONET Software Version 5.5. 2010. Available at: http://www.who.int/drugresistance/whonetsoftware/en. Accessed 19 Aug 10.

Associate Editor: Karen Spadari Ferreira

All the content of the journal, except where otherwise noted, is licensed under a Creative Commons License CC BY-NC. 